\title{
On the Training Model of China's Local Normal University Students during the Transitional Period from the Perspective of Happiness Management ${ }^{\mathrm{i}}$
}

\author{
Huang Weiwei \\ College of Teacher Education, Zhaoqing University, China
}

Copyright $(2016$ by authors, all rights reserved. Authors agree that this article remains permanently open access under the terms of the Creative Commons Attribution License 4.0 International License

\begin{abstract}
As a theory based on the hypothesis of "happy man" about human nature, happiness management plays a significant guiding role in the optimization of the training model of local Chinese normal university students during the transitional period. Under the guidance of this theory, China should adhere to the people-oriented principle, strengthen the cultivation of cultural literacy, establish growth community, and encourage "teaching by sharing" to stimulate the subjective initiative of normal university students, so as to help them become qualified teachers who can teach and educate students well.
\end{abstract}

Keywords Happiness Management, Local Universities, Normal University Students, Training Model

\section{Introduction}

The establishment of normal university has the longest history in China. In traditional sense, "normal university" mainly refers to the institution of higher education to cultivate teachers in various fields. However, in modern sense, "normal university" not only bears the mission of cultivating high-level teachers, but also gets a brand-new identification of comprehensive talent cultivation base. Normal university is changing from simply cultivating talents in arts, science, engineering and education before to comprehensive university. Due to the temporary saturation of social demands, normal university student gradually become the vulnerable group in all universities in China. China has long been known as an educational country rather than an educational power. One of the important reasons is that the rural elementary and secondary schools in China are confronted with educational issues such as the lack of teachers and irrational faculty structure, which have seriously impeded the overall improvement of the quality of education in China. In May 2007, the State Council decided to introduce free normal education policy at the normal universities directly under the Ministry of Education, with the hope of attracting outstanding young people to grass-roots communities for service. However, the real situation shows: currently, compared with those of key normal universities, there are more local normal university graduates choosing to go to rural areas and the grass-roots communities, filling most of the vacancies of rural education to make up for the lack of grass-roots teachers. ${ }^{[1]}$ Local normal university for undergraduates refers to the general institutes of higher education belonging to each province, autonomous region, direct-controlled municipality, special administrative regions like Hong Kong and Macao; most of them are supported by local finance, and get funds from local administrative departments. As the main part of higher education system in China, with the goal of providing service for the development of regional economic society, normal university is making efforts to cultivate high-quality talents for local places. In 2014, the Ministry of Education issued Guidance on the Transition and Development of Local Universities. The initiative aroused the first thoughts among local normal universities focusing on the training of elementary and secondary school teachers of their own development direction. In view of the above, it becomes a core issue that cannot be ignored by China's local normal universities during the transitional period how to correctly interpret the state policies and guidelines in order to improve the overall quality of normal university students.

\section{Happiness Management Theory}

The research on human nature based on western modern management theory is carried out from the perspective of people's purpose for working. The research focuses on the factors to which people attach most importance, and presents corresponding assumptions about human nature and management model. Among these, the most influential theories of human nature in sequence are economic man, social man, self-actualization man and complex man. While 
all these four "assumptions about human nature" do not reflect the essence of human nature which refers to people's most essential pursuit and ultimate goal in life and work. Since the core of management is to manage human, and in essence it refers to motivate people's enthusiasm and initiative through meeting their requirements so as to realize the effective allocation of organization resources maximize organization performance. From the perspective of psychology, human has the tendency of self-preservation. Human's primary nature is to pursue happiness while avoid bitterness. So, happiness is the ultimate goal of all activities; happiness is the ultimacy. This also makes the ultimate foothold od management should and also must be put on human nature and management should explore how to meet human's requirements and motivate their vitality and potential to an extreme ${ }^{[2]}$. From this perspective, the ultimate human nature assumption in management is "people in happiness". And the ultimate significance of management is to change human life and to make them acquire happiness and joyfulness. Therefore the management formed based on the assumption of people with happiness - happiness management. Happiness management is a new management philosophy and management model. There is still no a certain consensus on the understanding of its definition and nature. Happiness management, as a new stage of management development, is not only an organic combination between management and ethic, but also a perfect integration of people and people, people and issue, people and thing. Furthermore, happiness management not only pursues the profit-winning goal in management, but also focuses on human's instinct, desire, self-esteem and value. It is both a value and methodology. Moreover, it complies with the law of human nature and respects human subjectivity. It views organization members as both the first object and the subject of organization and management; The essence of happiness management lie in the concepts including motivation people, self-actualization people, culture people and happiness people. It takes full advantage of the initiative, enthusiasm, creativity of organization members, and organically unifies individual goal, group goal and organization goal together. The essence is to change human life and provide happiness and joyfulness to them. From the perspective of Organizational Behavior, happiness management focuses on the goal of development in three layers including individual, group and organization. Through motivating people' $\mathrm{s}$ potential and molding high-quality people, the happiness of human in material aspect, the happiness of group in society and the happiness if organization in value can be achieved. Therefore, we arrive at the ultimate function of management, based on which it can promote the comprehensive progress and accord development of society.

The concept of happiness management was first derived from discussions of happiness among the ancient Greek sages, who held that only happy lives were truly meaningful and valuable, and that happiness itself could be achieved.
With the development of modern positive psychology and the introduction of positive organizational behavior and other related concepts, the notion of happiness management has gradually extended to related areas and drawn the attention of scholars. Chinese scholar Pu Dexiang made an in-depth analysis of happiness management theory, believing that happiness management is a mechanism and process of giving full play to and making full use of every member's wits and advantages to coordinate the organization's resources in order to promote the maximization of happiness of the stakeholders. ${ }^{[3]}$ The main content of happiness management theory includes: (1) respect for the objectivity and subjectivity of members of the organization; (2) people-oriented principle by giving play to people's initiative and promoting the development of their potential, the enhancement of their overall quality and realization of their self-worth; (3) unity of personal and organizational goals and optimal use of resources to create greater social value. $\mathrm{Pu}$ Dexiang pointed out that the happiness maximization of the stakeholders of an organization could only be obtained by the interaction and combination between the cost minimization of its structural information and of the lives of its members, so that management can reach the optimal level. ${ }^{[4]}$

\section{Analysis of the Status Quo of the Training Model for Normal University Students from the Perspective of Happiness Management}

The operating mechanism of local normal universities is the interaction among managers, teachers and students on the basis of particular training model, and the effectiveness of the interaction is reflected in whether the training objectives of normal universities can be realized. Mr. Dai Liyi held that the training objectives should be based on the selection and training of teachers who are fond of, fit for and good at teaching in order to lay a solid foundation for them to gradually grow to be outstanding teachers ${ }^{[5]}$. This shows the content of happiness management theory exactly coincides with the training objectives of normal universities. By analyzing the current training model for normal university students through happiness management theory, the following problems can be found:

\subsection{The Overall Quality of Normal University Students Is Not Optimistic, with Low Competitiveness}

As a "person-to-person" job, teaching has obvious individual characteristics. Due to this, good teachers with both political integrity and professional competence can exert more positive and far-reaching impacts on students, who should have lofty professional ethics, outstanding subject teaching ability, unremitting professional 
development enthusiasm and capability and excellent subject leadership. ${ }^{[6]}$ Therefore, higher requirements should be put forward for education practitioners who need to possess higher comprehensive quality. At present, however, the overall quality of local normal university students is not optimistic: (1) the source of students is of poor quality and shows a significantly downward trend ${ }^{[7]}$ Local normal universities have low employment competitiveness and narrow employment opportunities, coupled with the impacts of various other factors like recruitment, salary and social evaluation system, unable to attract outstanding talents; (2) for a long term, local normal universities have ignored the "normal quality" of their students, so that normal university students under the current training model are exposing more and more problems after teaching. The general response from elementary and secondary schools is that new teachers not only lack teaching skills, but also need to enhance cultural literacy; (3) under the guidance of relevant policies, the current teacher education reform puts more emphasis on the improvement of explicit qualities of normal university students (knowledge and skills, etc.), than on the cultivation of implicit qualities (professional ethics, awareness and attitudes, etc.). Some research results reveal that normal university students have an advantage in "able to teach" but are apparently at a disadvantage in "good at teaching" and "willing to teach". ${ }^{[8]}$

\subsection{The Teacher-Student Relationship Shows an Adversarial Tendency}

As Zankov put it, with regard to the effect of educational work, it is very important to see how teachers and students get along with each other. At present, China's local normal universities fail to fully arouse the enthusiasm of the teachers about teaching, and thereby lead to an adversarial relationship between teachers and students. The causes are as follows: (1) without reasonable evaluation methods designed for local normal university teachers, scientific research workload is still the main indicator of teacher evaluation. Consequently, teachers stress scientific research but neglect education research, let alone the professional development of students; (2) as universities continue to increase enrollment, the number of students' increases out of proportion to that of teachers. The resulted big-class teaching reduces the interaction and communication between teachers and students, and thus weakens their emotional connections; (3) under the influence of the idea of Mechanism, a "contractual relationship" is formed between teachers and students in normal universities, which separates the goals of teachers and students. As a result, teachers become trainers of human capital, while students take involvement in education activities as a stepping-stone to their future career; (4) normal university students have been bored with the cramming, spoon-feeding teaching model in elementary and secondary school, which thus breeds more hostility toward teachers who follow this teaching model in university. In this case, both teachers and students are flooded with complaints and grievances, accompanied by a drop in happiness index. Such a teacher-student relationship not only hinders the achievement of the training objectives, but directly affects the future teaching career of normal university students.

\subsection{Normal University Students Are Short of Intrinsic Motivation for Learning}

Deci \& Ryan in their Self-Determination Theory (SDT) divided motivation into autonomous motivation and controlled motivation, of which the latter is controlled by extrinsic rewards and punishments, while the former has more positive, long-term effects; motivation cannot be converted to inner psychological needs if not internalized, and then its role will fade away as the extrinsic factors disappear. ${ }^{[9]}$ Some scholars pointed out: normal university students who hold a strong sense of teachers' professional identity and volunteer to engage in teaching in the future attach more importance to the intrinsic value of the teaching profession, believe that they are fit for this job, and meanwhile are proud that they will become a teacher. Such a sense of self-efficacy inspires a strong sense of responsibility. Only in this way can they be truly intrinsically motivated to study. So far, however, there are problems in both extrinsic incentives and constraints of normal university students' learning motivation system. Similar to comprehensive universities, local normal universities overemphasize postgraduate qualifying examination rate and employment rate in their evaluation systems, so that normal university students devote more energy to dealing with employment pressure and take certificates as the motivation for learning. As a result, students become eager for quick success and instant benefits. The management system based on the hypothesis of "evil humanity" is characterized by "restriction" and "obedience", in a drive to restrict the bad behavior by setting strict rules, and then encourage good behavior and habits in normal university students. Nevertheless, this management system often cannot achieve the purpose of guiding the development of normal university students into good aspects and giving full play to or training their ability; instead, it strengthens their rebellious mentality, and thereby restricts their healthy personality development and dampens their learning initiative. As a matter of fact, local normal universities ignore the "normal" guidance to their students, which naturally leads to the fact that normal university students cannot take the sense of mission of becoming a teacher as their own intrinsic motivation, and thus are short of motivation for learning.

\section{Strategies for the Optimization of the Training Model for Normal University Students}

Happiness management theory holds that the fundamental goal and ultimate meaning of people's work and lives is to 
pursue the maximization of happiness. In other words, happiness is the ultimate goal of all human activities and has the ultimate significance. In this sense, the ultimate purpose of management is to make people happy by changing their lives. ${ }^{[10]}$ Therefore, only teachers who have both happiness and capacity can truly promote the development of education; otherwise, incalculable negative effects may occur. In order to handle existing problems in the traditional training model, it is necessary to reduce the information costs and life costs of the training of normal university students and meanwhile increase the effectiveness of the training from the perspective of happiness management theory. Specifically, improvements can be made from the following two aspects.

\subsection{Strengthen Cultivation of Cultural Literacy Based on People-oriented Principle}

\subsubsection{Arouse Students' Initiative Based on People-oriented Principle}

Either the student-based concept or the teacher-based concept belongs to the people-oriented concept. In fact, normal university students already have independent personalities, and they carry the brand of the times as the post-90s generation. With their subjective awareness continuously increasing, they are very difficult to control in management, which thereby highlights the importance of self-discipline. ${ }^{[11]}$ Therefore, the new training model should be developed on the basis of respect for the humanity of normal university students, abidance by the law of humanity development and encouragement of their subjective initiative. The students should have their own wishes respected when filling in the application for college entrance, choosing the major and the courses. The new training model should be based on and aimed at the promotion of the healthy growth of normal university students. In addition, local normal universities should change the "parental authority"-styled management model so that students can participate in the development of the new training model and giving full play to their role as masters. At the same time, more efforts should be made to enhance the general sense of efficacy of teaching profession among the students, and thus help them develop a lasting motivation for learning.

\subsubsection{Enhance Cultivation of Cultural Literacy and Improve Students' Personality}

Normal university students are the reserve army for China's future education. The object of education is not dead machines but live people. Thus, teachers need to have both of the two major functions: "teaching" and "education". In the context of "quality-oriented education", teachers are required to have higher quality and stronger hearts in a more urgent way. It is therefore essential to care for the psychological health of normal university students and enrich their spiritual world, especially for those growing up in the examination-oriented education environment. Besides, local normal universities should establish a good cultural environment, respect the personalities of normal university students which are individualized, staged and evolutionary, and regularly carry out research activities that are closely linked to the characteristics and problems reflected in the current development of normal university students. In particular, various forms of campus cultural activities should be organized around all aspects of the training of normal university students from part to whole, with the purpose of stimulating their potential as well as enhancing their cultural literacy.

\subsection{Establish Growth Community and Encourage "Teaching by Sharing"}

\subsubsection{Integrate Goals and Establish Growth Community}

Special-grade teacher Zhang Siming said, "As a teacher, happiness should be to continuously surpass oneself and be surpassed by students." For the part of normal university students, they are individuals whose values have not been clearly established, and thus are badly in need of the guidance of teachers. They long for a teacher-student relationship of mutual respect, trust, equality and care. At this point, "teacher-and-student growth community" precisely adapts to the needs, which aims to promote common development through effective interaction between teachers and students under the premise of a shared vision. As Bloom wrote, "The real community of man, in the midst of all the self-contradictory simulacra of community, is the community of those who seek the truth, of the potential knowers...of all men to the extent they desire to know." ${ }^{[12]}$ Everyone needs to advance with the times, learn and grow in practice. This philosophy is exactly embodied in the saying of "teaching while learning".

\subsubsection{Encourage "Teaching by Sharing"}

In the traditional sense, classroom teaching focuses on teacher's teaching, but the difference between teaching and sharing is that teachers and students play different roles and parts, and teaching content involves different aspects. In teaching-based classroom, teachers play an active role while students play a passive role, which causes inadequate interactions between teachers and students; meanwhile, teaching content is more about professional theoretical knowledge. In sharing-based classroom, on the contrary, teachers and students enjoy an equal relationship: students can raise questions about things shared by teachers and put forward their own views, of which things shared can be knowledge and skills or emotional feelings. As an attitude toward life as well as a teaching method, sharing helps to fully respect the uniqueness of each individual of normal university students; in the meantime, laying down the so-called teacher's dignity, teachers can accept the limitations of their knowledge and experience and listen to the views of others, instead of determining things on their own.

It takes ten years to grow trees, but a hundred to cultivate 
people. As a cause to be passed on from generation to generation, education is such a long process from sowing to flowering and then fruiting that the cumulative effect is more significant in education. Happiness management, as a theory based on the hypothesis of "happy man", has important theoretical significance in guiding and promoting the realization of self-worth of normal university students. Local normal universities should be fully aware of the significance of this theory and carry it out in the establishment of the new training model for normal university students, so as to create a harmonious and happy environment for the cultivation of normal university students, in order that they can go smoothly in their future professional development.

\section{REFERENCES}

[1] Zhao Wenwen. On the Structural Imbalance between Supply and Demand of Normal College Graduates in West China [D]. Chengdu: Sichuan Normal University, 2009: 53.

[2] Li Chaobo. Happiness Management: A Discuss of Concept and practice [J]. Law and Economy, 2012, (9): 104.

[3] $\mathrm{Pu}$ Dexiang. The Evolution of Humanity in Theories of Management and Interpretation of Happiness Management [J]. Journal of Dalian University of Technology (Social Sciences), 2009 (3): 56-60.

[4] $\mathrm{Pu}$ Dexiang. The Evolution of Humanity in Theories of Management and Interpretation of Happiness Management

Fund Program: Guangdong Provincial Featured Innovation Project (education research) (Project No.: 2014GXJK151); Guangdong Provincial Committee of the Communist Youth League and Guangdong Provincial Department of Human Resources and Social Security Special Project (Project No.: GQY1337); 2015 Zhaoqing Municipal Annual Planned Project of Philosophy and Social Sciences (Project No.: 15ZC-02).
[J]. Journal of Dalian University of Technology (Social Sciences), 2009 (3): 56-60.

[5] Dai Liyi. Training of Normal College Students: Content, Process and Security [J]. Teacher Education Research, 2011, 23 (5): $1-5$.

[6] Xie Manlan. A Comparative Study of Criteria for Outstanding Teachers - A Case Study of English Teachers [J]. Journal of Guangdong Education Institute, 2013 (4): 5.

[7] Gao Yabing, He Weiqiang. Problems in and Suggestions on the Training of Normal College Students after Normal Colleges Expanded into Comprehensive Universities [J]. Journal of Zhejiang International Studies University, 2010 (2): $1-6$.

[8] $\mathrm{Yu}$ Zhen, Wei Jianguo, Qu Hangyu. Evaluation from Elementary and Secondary School Teachers on the Status Quo of the Quality of Normal College Students - With the Case Study of Elementary and Secondary School Teachers in Six Provinces of Central China [J]. Contemporary Teacher Education, 2014 (4): 68-71.

[9] Deci E. L., Ryan R. M. Self-Determination Theory: A Macrotheory of Human Motivation, Development, and Health [J]. Canadian Psychology, 2008 (3): 182 - 185.

[10] Deci E.L., Ryan R.M.Self - Determination Theory: A macrotheory of human motivation, development, and health[J].Canadian Psychology,2008( 3) : $182-185$.

[11] Pu Dexiang. Analysis of Happiness Management in Business Organizations [J]. Journal of Yunnan University of Finance and Economics, 2009 (6): 127-133.

[12] Allan Bloom. The Closing of the American Mind [M]. Nanjing: Yilin Press, 2007: 330. 